\section{Not just another primary care workforce crisis ...}

There is a baffling disconnect in the position of Irish and Purvis on the primary care workforce crisis. ${ }^{1}$ On the one hand, they say:

'The supply of newly qualified GPs is unlikely to match demand without international recruits and returners to the GP workforce.

On the other hand, many readers of this Journal will be astonished to learn the obstacles faced by UK-trained GPs who wish to return to England (but not Wales or Scotland, see below) after working as GPs for a period over 2 years in countries such as Australia, New Zealand, and Canada.

Briefly, they have to register for a local returners scheme, take a knowledge-based multiple choice question (MCQ) in London, wait for the results of that, then apply to do a basic objective structured clinical examination (OSCE) in London, wait for the results of that, then have a clinical interview with a regional educational supervisor and then, if all is deemed satisfactory, be signed off as fit to work, all the while idle at their own expense over a period of up to 6 months. This returners policy has been implemented by the Committee of General Practice Education Directors (COGPED), a body to that Irish and Purvis belong, with no attempt to distinguish at entry between a doctor who has been, say, on maternity leave and not working for 5 years and one who has been doing mainstream first world general practice in a comparable health economy. Arguments that the latter individual requires 'refamiliarisation' with the NHS are specious as no such 'refamiliarisation' is offered during the period they remain idle, their clinical skills atrophying. Further, knowledge of NHS procedures and protocols is not assessed by the MCQ and OSCE, which are basic clinical exams. Many would argue, too, that 'refamiliarisation' is not as complex a task as COGPED would have us believe and could easily be dealt with in many ways such as online learning modules or a short face-to-face course.

I suggest that Irish and Purvis reflect on the absurdity of COGPED's position and that if they are serious about tackling the workforce crisis they put in place a workable scheme for experienced UK-trained GPs returning from working in comparable health economies. Meanwhile, both Wales and Scotland take a far more pragmatic approach and will assess returning GPs on their merits via a clinical interview and do not require the $M C Q$ and $O S C E$, with the attendant period of costly, enforced idleness, as standard.

Either Irish, Purvis, and their colleagues on COGPED will put in place a more sensible regime to relicense UK GPs returning from abroad or we really will be in the workforce mire. In England, anyway.

\section{David Berger,}

MRCGP, Exmoor Medical Centre, Fishers Mead, Dulverton, Somerset, TA22 9EN.

E-mail: davebergerdamail.com

\section{Competing interests}

I may wish to work abroad and may wish to return one day. I have had previous correspondence on this issue with Irish and COGPED.

\section{REFERENCE}

1. Irish W, Purvis M. Not just another primary care workforce crisis ... Br J Gen Pract 2012; 62(597): 179-179.

DOI: 10.3399/bjgp12X641302

Irish and Purvis' have written a useful article summarising the imbalance between GPs entering and leaving the GP workforce, and indicate that this imbalance is likely to worsen in the next few years. The problems that the deaneries face now are acute and have serious implications for future recruitment of GPs at surgeries, and hence the viability of clinical services. There are two other dynamics in play that make the situation even more challenging than they describe.

First, many new roles are opening themselves up to GPs, and they currently sit somewhat uncomfortably alongside the traditional service roles of the general medical services and Personal Medical Services contracts. As a speciality we have accommodated training for many years. We have just about got enough appraisers. We have so far been able to recruit senior GPs to lead clinical commissioning groups. We have medical directors who are system leaders but nearly all of them are coping with too much work la lot of it protracted and complex) for the time they have available. All these additional roles are useful and interesting, and do contribute to patient care and safety. However, they all take GPs away from direct clinical work.

We have always seen some drift of GPs to post overseas, or moves sideways to other specialities such as occupational health.

So as a speciality we have many new roles opening up to all GPs, and we still have the patients to see. There may not be enough of us to go round all these roles. ${ }^{2}$

Secondly, we have a primary care service that is poorly configured in terms of its structures and processes to achieve the outcomes that both doctors and patients want and need. We have GPs working flat out in their surgeries coping with the daily treadmill of acute reactive demand. We know that there is much unmet need, but we feel so busy that meeting it can seem an impossible challenge. Our supposed 10minute consultations already average 11.7 minutes, and still fail to fully address all the problems patients have, and the comorbidity that needs addressing. We can see the challenges of age, complexity, and comorbidity are going to increase, and we are not well set up even for current demands. The GP's work is not well integrated with the specialist nurses available in primary care. Too often they are hospital outreach staff directed by consultants, rather than GPs. There are developing tools such as the Bolton Dashboard and the BUPA/Nuffield predictive risk management software that will in future allow us to ask 'who needs to be seen today?' as opposed to 'who's booked in today?'. But at present in our surgeries we are lumbered with the burden of acute reactive medicine and we struggle to see past our list of patients. And our work with our specialised nursing colleagues is not yet fully effective, and their work is not always best targeted.

So we see an ill-configured and specified primary care service with rising clinical and managerial demands on it, trying to meet it with too few staff. This scenario is 
intrinsically unstable, and a new settlement for primary care will soon become necessary.

\section{Peter Davies,}

GP, FRCGP, Keighley Road Surgery,

Illingworth, Halifax.

E-mail: npgdavieslablueyonder.co.uk

\section{REFERENCES}

1. Irish W, Purvis M. Not just another primary care workforce crisis ... Br J Gen Pract 2012; 62(597): 179-179.

2. Davies P, Moran L, Gandhi H. What is the work of primary care? In: The new GP's handbook. London: Radcliffe Medical Publishers, 2012.

DOI: 10.3399/bjgp12X641311

\section{Authors' response}

Thanks Peter.

Your point is well made. We have recognised the potential for extended roles of the GP, but the word limit was against us!

I think we could go further and point out that training too few/too many GPs is a binary decision but with unequal risk and consequence, in other words, too few GPs and the NHS implodes ... train 'too many' GPs and the flexible, adaptable, entrepreneurial nature of GPs is that they add value through extended roles, enhanced roles, and intermediate care roles. So you can have too few GPs with apocalyptic consequences ... but you can never really have too many GPs!

Hey, if we have enough GPs we may even be able to reconnect with urgent and unscheduled care out of hours.

\section{Mark Purvis,}

Yorkshire and the Humber Deanery, School of General Practice, Willow Terrace Road, University of Leeds, Leeds, LS2 9JT.

E-mail: Mark.Purvislayorksandhumber.nhs.uk

Bill Irish,

School of Primary Care, Severn Deanery, Frenchay Hospital, Bristol.

DOI: 10.3399/bjgp12X641320

\section{The BJGP}

One of the pleasures of being an honorary fellow of the College is that I receive a copy of the Journal, and, although deluged like everybody else with written material, I read it. I was an editor for 25 years, and as such I have a few observations on the Journal that may prompt some useful thoughts.

First, I notice that your editorial board has 17 members lassuming that you and your deputy are members), and yet there are only two women. Surely this is an embarrassingly low number. Judging by the names, I think that only one member comes from an ethnic minority. You are failing to reflect British general practice. I suggest that you scrap your board and make a fresh start. As I discovered, copying Margaret Thatcher in her abolition of the Greater London Council, it is easier to get rid of the whole lot than just one or two.

Secondly, I'm impressed that in your Editor's Briefing you have managed to make safety-net a verb. Truly there is no noun that can't be verbed.

Thirdly, what is the neo-liberal London consensus', which Calum Paton writes about?' This reminds me of my days as a communist, but I suggest that it is a figment of Paton's imagination. He also refers to GPs being 'sold the dream of power only to find it has become responsibility'. But did any GP think it possible to have power without responsibility? I can't think so. In short, I think that this article would have benefited from tighter editing.

Fourth, the word cloud of the Journal contents is very interesting, but what may matter most is what's not there. Rob Atenstaedt notices the absence of any mention of countries outside the $\mathrm{UK}_{1}{ }^{2}$ and I noticed the absence of safety, internet, comorbidity, and commissioning.

Richard Smith,

35 Orlando Road, London, SW4 OLD.

E-mail: richardswsmithlayahoo.co.uk

\section{REFERENCES}

1. Paton C. Competition and integration: the NHS Future Forum's confused consensus. Br J Gen Pract 2012; 62(596): 116-117.

2. Astenstaedt R. Word cloud analysis of the BJGP. Br J Gen Pract 2012; 62(596): 148.

DOI: 10.3399/bjgp12X641339

\section{Editor's response}

Richard Smith's editorial lineage goes back 25 years, and mine a bit longer, to the clinical editorship of World Medicine in the early 1980s - nothing like a bit of badinage between two old hacks.

We are aware of the demographic asymmetry in the editorial board and do our best by advertising nationally for new members - but as for sacking my splendid colleagues, this isn't the BMJ!

Diagnostic safety-netting was a term coined by Roger Neighbour in his seminal Inner Consultation' and is a useful neologism which is firmly embedded in describing the diagnostic processes of primary care. $^{2}$

Calum Paton can comment for himself about the neo-Liberal consensus and power vis a vis responsibility, but tighter editing by me would have stopped short at changing this sentence - general practice unfortunately has a long record of the exercise of power through claims to autonomy and clinical freedom without fiscal responsibility.

And finally all those terms missing from the cloud are very much on our minds, and all will appear in the titles of articles and papers to be published in the next few months.

Roger Jones,

Editor of the British Journal of General

Practice, 1 Bow Churchyard, London,

EC4M 9DQ. E-mail: journaldarcgp.org.uk

\section{REFERENCES}

1. Neighbour R. The inner consultation. 2nd edn. Oxford: Radcliffe Publishing, 2004.

2. Almond S, Mant D, Thompson M. Diagnostic safety-netting. Br J Gen Pract 2009; 59(568): 872-874.

DOI: 10.3399/bjgp12X641348

\section{Author's response}

Richard Smith suggests that only communists and fantasists may detect a'neo-liberal London consensus'. He goes on to suggest that the BJGP is UK-centric. May I suggest that his US-corporate-forprofit-health-care-tinted spectacles have actually stopped him seeing the UK health systems in the round, from which perspective the English obsession with recycling increasingly surrealist versions of failed 'market reform' models is quite striking. First rule of comparative health care: use it to understand yourself better!

'The London consensus' was of course my tart take on the well-known coinage, 